\title{
BMJ Open What do women know before getting pregnant? Knowledge of preconception care and associated factors among pregnant women in Mana district, Southwest Ethiopia: a community-based cross-sectional study
}

Firanbon Teshome (D), Yohannes Kebede, Fira Abamecha, Zewdie Birhanu

To cite: Teshome F, Kebede $Y$, Abamecha F, et al. What do women know before getting pregnant? Knowledge of preconception care and associated factors among pregnant women in Mana district, Southwest Ethiopia: a community-based crosssectional study. BMJ Open 2020;10:e035937. doi:10.1136/ bmjopen-2019-035937

- Prepublication history for this paper is available online. To view these files, please visit the journal online (http://dx.doi org/10.1136/bmjopen-2019035937).

Received 22 November 2019 Revised 14 April 2020 Accepted 17 June 2020

\section{D) Check for updates}

(C) Author(s) (or their employer(s)) 2020. Re-use permitted under CC BY-NC. No commercial re-use. See rights and permissions. Published by BMJ.

Health, Behavior and Society, Jimma University, Jimma, Ethiopia

Correspondence to Mr Firanbon Teshome; firanbonteshome@gmail.com

\section{ABSTRACT}

Objective To assess knowledge of preconception care and associated factors among pregnant women in Mana district, Jimma zone, Oromia Region, Southwest Ethiopia, in 2019.

Design A community-based cross-sectional study was conducted from 2 March to 10 April 2019.

Setting The study was conducted in Mana district. Eight rural Gandas and one urban Ganda were included in the study.

Participants Out of 715 pregnant women in the selected rural Gandas, 553 participated in the study, whereas 70 out of 88 were recruited from the urban Ganda. A total of 623 pregnant women participated in the study.

Primary and secondary outcome measures Women's knowledge of preconception care was determined. Descriptive statistics were calculated as necessary. Logistic and linear regression analyses were used to identify the association of women's knowledge of preconception care with explanatory variables.

Results Among 623 respondents, 133 (21.3\%) of pregnant women had good knowledge of preconception care. Multivariable linear regression analysis showed that women who attended secondary and above education $(\beta=3.6 ; p<0.001)$ and those for whom their husbands attended secondary and above education $(\beta=2.3$; $p=0.001)$, planned pregnancy status $(\beta=1.2 ; p=0.005)$, being on follow-up for pre-existing medical illnesses $(\beta=1.5 ; p=0.014)$ and having four or more antenatal care visits $(\beta=0.4 ; p=0.016)$ were significantly associated with women's knowledge of preconception care.

Conclusion The findings imply that providing health education and health promotion for women is important to improve their level of knowledge of preconception care.

\section{BACKGROUND}

Preconception care (PC) is a biomedical, behavioural and social health intervention provided to women and couples before conception occurs which helps improve their health status, and reduce harmful behaviours,
Strengths and limitations of this study

It is a community-based study that makes it a representation of the true population.

- Both the urban and rural populations were included which help for the generalisability of the findings to the district as a whole.

- In this study, we used both logistic and linear regression analyses which help for the robustness of the findings.

- Recall bias may occur on some questions such as those related to obstetric and gynaecologic factors as pregnant women were asked for history before they conceived.

Interviewer bias may also have occurred.

and individual and environmental factors that could contribute to poor maternal and child health outcomes. ${ }^{1}$ It includes the care before the pregnancy and the care between the subsequent pregnancies. ${ }^{2}$ It is ultimately aimed to improve maternal and child short and long-term health outcomes. ${ }^{1}$ This can be achieved through its main components: risk assessments (evaluation of medical history such as reproductive life plan; medical and family history; medication use; general physical assessment; and vaccination history); counselling or promoting healthy lifestyle (reducing pregnancies that are too early and too close, reducing unplanned pregnancies, improving sexual health and behaviour; supplementation of micronutrients; healthy weight; nutrition; exercise; tobacco and alcohol cessation); and interventions/ management for the identified risks. ${ }^{134}$

Despite the target of the sustainable development goal to reduce the global maternal mortality ratio to less than 70 per 100000 
live births by the year 2030, globally in 2015, about 303000 mothers died from pregnancy and childbirthrelated causes and $99 \%$ of the deaths occurred in low and middle-income countries, with sub-Saharan Africa alone accounting for roughly $66 \% .{ }^{56}$ Even though several factors could exist, lack of PC can be one of the reasons for high maternal and child morbidity and mortality. ${ }^{1}$ Ethiopia is also one of the countries with a high maternal mortality rate (412 deaths per 100000 live births), child mortality rate (67 per 1000 live births) and neonatal mortality rate (29 per 1000 live births) ${ }^{7}$ PC can serve to reduce these problems by optimising maternal, child and neonatal health status. ${ }^{8}$

PC helps fill the gap in the existing continuum of maternal and child healthcare. ${ }^{3}$ For instance, antenatal care (ANC) often starts too late to prevent serious maternal and child health problems, thereby neglecting the most critical time of embryonic growth and development. ${ }^{9}$ By the time most of the women recognise their pregnancy, most of the fetal organs have been formed. ${ }^{10}$ In Ethiopia also the median month for the first ANC visit is 4.7 months. ${ }^{7}$ This gap can be filled if the PC is properly implemented. PC is an evidence-based intervention targeting the critical periods of the infant's organ formation. ${ }^{1}$ It is the earliest link between maternal and newborn health, and a window of opportunity that can improve women's health before, during and after pregnancy by providing a chance for early identification of the risks, counselling and intervention/management for the identified risks and, if indicated, referral to specialised PC. ${ }^{31}$ In addition, $\mathrm{PC}$ also helps reduce maternal adverse pregnancy outcomes (abortion, anaemia during pregnancy, maternal mortality, and so on) and neonatal and child adverse pregnancy outcomes (low birth weight, preterm baby, stillbirth, neonatal and child mortality, and so on). ${ }^{12}$ Indeed, it is highly associated with increasing utilisation of other services like ANC, delivery care and postnatal care. ${ }^{13}$ Despite all these advantages, and recommended by the $\mathrm{WHO},{ }^{1} \mathrm{PC}$ has not been widely implemented especially in low and middle-income countries. ${ }^{14}$ In Ethiopia also little is known about women's knowledge of PC. Therefore, this study aimed to assess the level of knowledge of PC and associated factors among pregnant women which will potentially serve to rethink about maternal and child health systems at policy, programme and management levels, helping to fill knowledge gaps and promote healthy behaviours.

\section{MATERIALS AND METHODS \\ Study design}

A community-based cross-sectional study was conducted from 2 March 2019 to 10 April 2019 in Mana district among pregnant women. Mana district is one of the 21 districts found in Jimma zone, Oromia Regional State. It is located $368 \mathrm{~km}$ southwest of Addis Ababa and $22 \mathrm{~km}$ from Jimma town. According to the 2019 report obtained from the Mana district health office, the district has a total population of 197 911, of which 26451 were urban and 171460 were rural. Women of reproductive age groups of the district were 43738 and pregnant women were 6868 . The district has a total of 26 Gandas: 1 urban Ganda and 25 rural Gandas. It has 7 health centres, 26 health posts, 11 private clinics and 3 private pharmacies. It has also 68 health extension workers and 121 healthcare providers of different professions.

\section{Participants}

The source populations were all pregnant women who were residing in Mana district during the study period. The study populations were randomly selected pregnant women among all pregnant women residing in the district and who fulfil the inclusion criteria. All pregnant women who lived in the district at least 6 months prior to the study period were included in the study. Pregnant women who were critically ill and unable to communicate were excluded.

\section{Patient and public involvement}

Patients and/or the public were not involved in this study.

\section{Recruitment procedures}

Epi Info V.7.1.1 was used to determine the sample size based on the following assumptions: $50 \%$ proportion was taken since there were no prior studies conducted on knowledge of PC among pregnant women in Ethiopia, 95\% level of confidence, $5 \%$ margin of tolerable sampling error, $10 \%$ non-response. Additionally, 1.5 design effect was considered as a rule of thumb in order to correct estimated sampling variance because of the two levels of a random selection of Gandas and the proportionate random selection of participants from each selected Ganda. Finally, the calculated sample size becomes 636 .

In order to select the study participants, first, the 26 Gandas were stratified into rural and urban. Then, the urban Ganda was included in the study purposively for representation. Eight Gandas among the 25 rural Gandas were selected by a simple random sampling technique. Then, the sample size was proportionally allocated to the selected nine Gandas. The lists of the total number of pregnant women registered in the selected rural Gandas were recruited from the family folder (health register which encompasses both individual and householdlevel health indicators) of the community health information system which is available at the health posts. For the urban Ganda, since the family folder did not exist a census was conducted to construct the sampling frame. Finally, computer-generated simple random sampling was used to identify the study participants. Their usual place of residence was identified in collaboration with Ganda leaders.

\section{Survey administration}

Data were collected using an interviewer-administered structured questionnaire which was adapted from different literatures ${ }^{15-18}$ and modified to the local context. An interviewer-administered questionnaire was used 
since the majority of the study participants were from rural areas and they were unable to read and write. It was first prepared in English and then translated to Afan Oromo and Amharic by experts and was translated back to English by another person to ensure its consistency and accuracy. Before the survey, a pretest was conducted on $5 \%$ of pregnant women in Saka district which is located 20 $\mathrm{km}$ away from the study area. A total of six data collectors (four clinical nurses and two BSc nurses) and two public health officers as supervisors were recruited for the study. The recruitment was based on their previous experience in data collection and fluency in the languages of the community. In addition, the principal investigator also closely supervised the data collection processes. The data collectors and supervisors were trained for 1 day on the objective of the study, data collection tool, approach to the interviewees; details of interviewing techniques; and respect and maintaining privacy and confidentiality of the respondents. Cronbach's $\alpha$ coefficient was computed to test the internal consistency of the tool and it was 0.88 , which is acceptable since a reliability coefficient of 0.70 or higher is considered acceptable. ${ }^{19}$

The dependent variable was women's knowledge of PC. The independent variables were sociodemographic factors, gynaecologic and obstetric factors, pre-existing medical illnesses, health facility-related factors and households' media access. In this study, women's knowledge of PC was measured based on the individual study participant's correct response of 19 items (HIV/AIDS testing and counselling; screening for hypertension, anaemia, diabetes mellitus, sexually transmitted infections, blood group, obesity, hepatitis B; stopping or removing family planning (if user); discussing with husband when to have a child; consulting health workers for advice; avoiding/ cessation of cigarette, alcohol, chewing khat; husband's health condition matters for healthy conceptions; taking balanced diet, iron, folic acid, tetanus vaccine) with response choices of 'Yes', 'No' and 'Do not know'. We scored 1 for each correct answer and 0 for each incorrect or 'Do not know' answer. Then, the composite knowledge score was produced by summing up, and the higher the score the higher the level of knowledge. The knowledge score for 19 questions ranged from 0 to 19, where 19 indicates all questions were answered correctly. Women who scored $50 \%$ and above ( $\geq 10$ correct responses to the 19 items) were recognised as 'women with good knowledge of $P C^{\prime}$ whereas those who score below 50\% ( $\leq 9$ incorrect responses to the 19 items) were considered as 'women with poor knowledge of $P C^{15}{ }^{15}$

\section{Data management and quality}

The option 'Don't know' was given to minimise recall bias. The principal investigator supervised the performance of data collectors on a daily basis. The collected data were checked for completeness, clarity and consistency by the principal investigator. Stratification of Gandas into urban and rural, and the use of a simple random sampling technique to select the rural Gandas and participants, and proportional allocation help reduce sampling bias.

\section{Data processing and analysis}

The collected data were entered, cleaned and checked using EpiData Manager V.4.0.2. and exported to SPSS V.21 for analysis. Descriptive analyses like mean, frequencies and proportions were calculated for different variables as necessary. Logistic and linear regression analyses were carried out by using the variables that were found to be associated with women's knowledge of PC in previous studies. ${ }^{1720-24}$ The binary models were first built for each explanatory variable with women's knowledge scores and variables with $\mathrm{p}$ value $<0.25$ (nine variables: residence, women's age, women's education, husbands' education, pregnancy planning status, family planning methods, frequency of ANC visits, pre-existing illness and media) were then taken to the multivariable logistic and linear models for analyses. Variables with $\mathrm{p}$ value $<0.05$ were recognised as significantly associated with women's knowledge of PC. Logistic and linear regression assumptions were checked and no violation was present.

\section{RESULTS}

\section{Sociodemographic characteristics of the study participants}

A total of 623 pregnant women participated, giving a response rate of $98.0 \%$. The mean $( \pm \mathrm{SD})$ age of the women was $27.2( \pm 5.0)$ years. More than half $(352(56.5 \%))$ were in the age range of $25-34$ years. A majority (553 (88.8\%)) of the respondents were living in rural areas. More than half $(328(52.6 \%))$ of the respondents had no formal education whereas only a few $(8(1.3 \%))$ attended college or university-level education. Most of the study participants $(462(74.2 \%))$ were housewives (table 1$)$.

\section{Obstetric and gynaecologic, and pre-existing medical illness of the study participants}

Of the total of 623 respondents, $98(15.7 \%)$ of the women had become pregnant for the first time. A majority (421 $(67.6 \%))$ of the women were multiparous. More than half $(351(56.3 \%))$ of the women had a history of using shortterm family planning methods. One hundred and thirtyfive $(21.7 \%)$ of the women had a history of four or more ANC visits. The current pregnancy was planned by 423 $(67.9 \%)$ of the women. Forty-six $(7.4 \%)$ of women had pre-existing medical illnesses (table 2).

\section{Women's knowledge of PC}

In this study, 133 (21.3\%) of the women had good knowledge of PC. Specifically, a majority (583 (93.6\%), 572 $(91.8 \%), 474(76.1 \%)$ and $383(61.5 \%))$ of the women had knowledge about HIV/AIDS screening, stopping/ removing family planning, discussing with their husbands about the pregnancy and screening for hypertension before a woman conceives, respectively. However, only $26(4.2 \%), 38(6.1 \%)$ and $91(14.6 \%)$ of the women had knowledge about taking folic acid, taking iron and 
Table 1 Sociodemographic characteristics of pregnant women in Mana district, Jimma zone, Oromia Region, Southwest Ethiopia, 2019

\begin{tabular}{|c|c|c|c|}
\hline Variable & Category & Frequency & $\%$ \\
\hline \multirow[t]{4}{*}{$\begin{array}{l}\text { Age of the } \\
\text { respondents }\end{array}$} & $\begin{array}{l}\text { Mean } \\
\text { age }=27.2 \text { years, } \\
S D=5.0\end{array}$ & & \\
\hline & $15-24$ & 196 & 31.5 \\
\hline & 25-34 & 352 & 56.5 \\
\hline & $35-49$ & 75 & 12.0 \\
\hline \multirow[t]{2}{*}{ Residence } & Rural & 553 & 88.8 \\
\hline & Urban & 70 & 11.2 \\
\hline \multirow[t]{3}{*}{ Religion } & Muslim & 583 & 93.6 \\
\hline & Orthodox & 28 & 4.5 \\
\hline & Protestant & 12 & 1.9 \\
\hline \multirow[t]{4}{*}{ Ethnicity } & Oromo & 580 & 93.1 \\
\hline & Dawuro & 21 & 3.4 \\
\hline & Amhara & 14 & 2.2 \\
\hline & Other* & 8 & 1.3 \\
\hline \multirow{4}{*}{$\begin{array}{l}\text { Educational } \\
\text { level of the } \\
\text { respondents }\end{array}$} & $\begin{array}{l}\text { No formal } \\
\text { education }\end{array}$ & 328 & 52.6 \\
\hline & $\begin{array}{l}\text { Primary education } \\
(1-8)\end{array}$ & 231 & 37.1 \\
\hline & $\begin{array}{l}\text { Secondary } \\
\text { education (9-12) }\end{array}$ & 56 & 9.0 \\
\hline & $\begin{array}{l}\text { Tertiary (college or } \\
\text { university) }\end{array}$ & 8 & 1.3 \\
\hline \multirow{4}{*}{$\begin{array}{l}\text { Main } \\
\text { occupation } \\
\text { of the } \\
\text { respondents }\end{array}$} & Housewife & 462 & 74.2 \\
\hline & Farmer & 106 & 17.0 \\
\hline & Merchant & 39 & 6.3 \\
\hline & Other† & 16 & 2.6 \\
\hline \multirow[t]{2}{*}{ Marital status } & Married & 618 & 99.2 \\
\hline & Other $\ddagger$ & 5 & 0.8 \\
\hline
\end{tabular}

*Kaffa, Gurage and Silte.

†Student, daily worker, private employee and government employee.

¥Single and separated.

screening for hepatitis B before a woman conceives, respectively (table 3 ).

\section{Factors associated with women's knowledge of PC}

Table 4 summarises the factors included in linear regression analyses. After adjusting for potential confounders in multiple linear regression analysis, the educational status of respondents and their husbands, current pregnancy planning status, frequency of ANC visits and follow-up for pre-existing medical illnesses were found to be statistically significant predictors of women's level of PC knowledge.

Even after controlling for confounding variables, the educational status of women and their husbands was found to be a significant predictor. Women who attended secondary and above education (adjusted $\beta=3.6 ; 95 \%$ CI
Table 2 Obstetric and gynaecologic, and pre-existing medical illness of pregnant women in Mana district, Jimma zone, Oromia Region, Southwest Ethiopia, 2019

\begin{tabular}{|c|c|c|c|}
\hline Variable & Category & Frequency & $\%$ \\
\hline \multirow[t]{2}{*}{ Gravidity } & Primigravida & 98 & 15.7 \\
\hline & Multigravida & 525 & 84.3 \\
\hline \multirow[t]{3}{*}{ Parity } & Null parous & 103 & 16.5 \\
\hline & Primiparous & 99 & 15.9 \\
\hline & Multiparous & 421 & 67.6 \\
\hline \multirow{5}{*}{$\begin{array}{l}\text { History of ANC } \\
\text { visit }\end{array}$} & Not on ANC visit & 217 & 34.8 \\
\hline & One visit & 42 & 6.7 \\
\hline & Two visits & 130 & 20.9 \\
\hline & Three visits & 99 & 15.9 \\
\hline & $\begin{array}{l}\text { Four or more } \\
\text { visits }\end{array}$ & 135 & 21.7 \\
\hline \multirow[t]{3}{*}{$\begin{array}{l}\text { History of family } \\
\text { planning use }\end{array}$} & $\begin{array}{l}\text { Not on family } \\
\text { planning }\end{array}$ & 173 & 27.8 \\
\hline & Short term & 351 & 56.3 \\
\hline & Long acting & 99 & 15.9 \\
\hline \multirow{2}{*}{$\begin{array}{l}\text { Pregnancy } \\
\text { planning status }\end{array}$} & Planned & 423 & 67.9 \\
\hline & Unplanned & 200 & 32.1 \\
\hline \multirow{2}{*}{$\begin{array}{l}\text { Pre-existing } \\
\text { medical illness }\end{array}$} & Yes & 46 & 7.4 \\
\hline & No & 577 & 92.6 \\
\hline
\end{tabular}

ANC, antenatal care.

2.2 to $5.0 ; \mathrm{p}<0.001)$ and those for whom their husbands attended secondary and above education (adjusted $\beta=2.3$; 95\% CI 1.0 to 3.6; $\mathrm{p}=0.001$ ) had higher knowledge scores of PC than those who had no formal education. The pregnancy planning status of women can also determine their knowledge of PC. Women who planned their current pregnancy (adjusted $\beta=1.2 ; 95 \%$ CI 0.4 to $2.0 ; p=0.005$ ) had higher knowledge scores of PC than their counterparts. Women's frequency of ANC visits was positively associated with higher knowledge scores (adjusted $\beta=0.4 ; 95 \%$ CI 0.1 to $0.8 ; \mathrm{p}=0.016$ ). Follow-up for pre-existing illnesses can significantly increase the knowledge scores of PC. Women who were on follow-up for their pre-existing illnesses (adjusted $\beta=1.5$; 95\% CI 0.3 to 2.8; $p=0.014$ ) had higher knowledge scores than their counterparts (table 4).

As shown in table 5, the multivariable logistic regression analysis also identified four predictors (women's education, current pregnancy status, frequency of ANC visit, follow-up for pre-existing illness) that were significantly associated with women's knowledge of PC. Only one factor (husband's education) which was predicted by multivariable linear regression analysis was not predicted by multivariable logistic regression analysis.

\section{DISCUSSION}

Women's health status before conception determines the pregnancy outcomes and health of future generations. 
Table 3 Knowledge of preconception care among pregnant women in Mana district, Jimma zone, Oromia Region, Southwest Ethiopia, 2019

\begin{tabular}{|c|c|c|c|}
\hline Variable & Category & Frequency & $\%$ \\
\hline \multirow{2}{*}{$\begin{array}{l}\text { HIV/AIDS testing and } \\
\text { counselling }\end{array}$} & Yes & 583 & 93.6 \\
\hline & No & 40 & 6.4 \\
\hline \multirow{2}{*}{$\begin{array}{l}\text { Stopping or removing } \\
\text { family planning (if user) }\end{array}$} & Yes & 572 & 91.8 \\
\hline & No & 51 & 8.2 \\
\hline \multirow{2}{*}{$\begin{array}{l}\text { Discussing with } \\
\text { husband when to have } \\
\text { a child }\end{array}$} & Yes & 474 & 76.1 \\
\hline & No & 149 & 23.9 \\
\hline \multirow{2}{*}{$\begin{array}{l}\text { Consulting health } \\
\text { workers for advice }\end{array}$} & Yes & 414 & 66.5 \\
\hline & No & 209 & 33.5 \\
\hline \multirow[t]{2}{*}{ Taking balanced diet } & Yes & 410 & 65.8 \\
\hline & No & 213 & 34.2 \\
\hline \multirow{2}{*}{$\begin{array}{l}\text { Screening for } \\
\text { hypertension }\end{array}$} & Yes & 383 & 61.5 \\
\hline & No & 240 & 38.5 \\
\hline \multirow[t]{2}{*}{ Screening for anaemia } & Yes & 318 & 51.0 \\
\hline & No & 305 & 49.0 \\
\hline \multirow{2}{*}{$\begin{array}{l}\text { Avoiding/cessation of } \\
\text { cigarette }\end{array}$} & Yes & 317 & 50.9 \\
\hline & No & 306 & 49.1 \\
\hline \multirow{2}{*}{$\begin{array}{l}\text { Avoiding/cessation of } \\
\text { alcohol }\end{array}$} & Yes & 294 & 47.2 \\
\hline & No & 329 & 52.8 \\
\hline \multirow{2}{*}{$\begin{array}{l}\text { Screening for diabetic } \\
\text { mellitus }\end{array}$} & Yes & 260 & 41.7 \\
\hline & No & 363 & 58.3 \\
\hline \multirow{2}{*}{$\begin{array}{l}\text { Avoiding/cessation of } \\
\text { chewing khat }\end{array}$} & Yes & 257 & 41.3 \\
\hline & No & 366 & 58.7 \\
\hline \multirow[t]{2}{*}{ Screening for STI } & Yes & 256 & 41.1 \\
\hline & No & 367 & 58.9 \\
\hline \multirow[t]{2}{*}{ Taking tetanus vaccine } & Yes & 158 & 25.4 \\
\hline & No & 465 & 74.6 \\
\hline \multirow{2}{*}{$\begin{array}{l}\text { Screening for blood } \\
\text { group }\end{array}$} & Yes & 134 & 21.5 \\
\hline & No & 489 & 78.5 \\
\hline \multirow{2}{*}{$\begin{array}{l}\text { Husbands' health } \\
\text { condition matters for } \\
\text { healthy conceptions }\end{array}$} & Yes & 132 & 21.2 \\
\hline & No & 491 & 78.8 \\
\hline \multirow[t]{2}{*}{ Screening for obesity } & Yes & 99 & 15.9 \\
\hline & No & 524 & 84.1 \\
\hline \multirow{2}{*}{$\begin{array}{l}\text { Screening for hepatitis } \\
\text { B }\end{array}$} & Yes & 91 & 14.6 \\
\hline & No & 532 & 85.4 \\
\hline \multirow[t]{2}{*}{ Taking iron/ferrous } & Yes & 38 & 6.1 \\
\hline & No & 585 & 93.9 \\
\hline \multirow[t]{2}{*}{ Taking folic acid } & Yes & 26 & 4.2 \\
\hline & No & 597 & 95.8 \\
\hline \multirow[t]{2}{*}{$\begin{array}{l}\text { Overall women's } \\
\text { knowledge of PC }\end{array}$} & $\begin{array}{l}\text { Good } \\
\text { knowledge }\end{array}$ & 133 & 21.3 \\
\hline & $\begin{array}{l}\text { Poor } \\
\text { knowledge }\end{array}$ & 490 & 78.7 \\
\hline
\end{tabular}

PC, preconception care; STI, sexually transmitted infection.
The majority of the problems occurring during pregnancy can be addressed before the women conceive. PC is an evidence-based health intervention that helps improve maternal and child health by reducing their morbidities and mortalities both in high and low-income countries. The knowledge of the community about healthcare services is very important in increasing their health-seeking behaviour, service utilisation and a healthy lifestyle.

The finding of this study showed women's knowledge was not consistent among the components of PC. For instance, the majority of the respondents knew that women should screen for HIV/AIDS (583 (93.6\%)), stop/ remove family planning (572 $(91.8 \%))$, discuss about the pregnancy with their husbands $(474(76.1 \%))$ and screen for hypertension before their conception (383 (61.5\%)). However, only some of them knew as women should screen for hepatitis B (91 (14.6\%)), and take folic acid $(26(4.2 \%))$ and iron $(38(6.1 \%))$ before they conceive. This inconsistency might be due to less attention given by healthcare providers to some services and the existence of more focus on other services. For example, conducting conferences and campaigns for some services like HIV/ AIDS screening by neglecting other services. It might also be due to the unavailability of some services at lower level health facilities like the health post, which is nearest to the community.

The finding of this study revealed that only $21.3 \%$ of the women had a good level of knowledge of PC. This finding was comparable with the study conducted in Hawassa, South Ethiopia (20\%). ${ }^{25}$ This might be due to both the studies included the urban and rural populations. It might also be probably due to the similarity of the lifestyle of the study participants. But it was lower than the study conducted in Adet town, Northwest Ethiopia (27.5\%). ${ }^{26}$ This difference might be due to the study conducted in Adet town included only the urban population while the current study included both the urban and rural populations. It might also be due to the larger sample size in the current study.

The finding of this study was higher than studies conducted in Iraq $(3.3 \%),{ }^{27}$ Iran $(10.4 \%)^{28}$ and Sudan $(11 \%) .^{29}$ This inconsistency might be due to the difference in the study period and sociocultural factors. It might also be due to the small sample size in the previous study. However, this study was lower than the study conducted in Zambia $(47.4 \%) .{ }^{30}$ This might be due to the difference in the study population. The study from Zambia was conducted on patients with diabetes on follow-up and frequent contact with healthcare providers increases the chance of obtaining information. It might also be due to the high attention given by healthcare providers to clients having chronic illnesses. Individuals with chronic illness might also gather information about their health issues. This study was also lower than studies conducted in Nigeria $(63.5 \%),{ }^{17}$ Malaysia $(51.9 \%),{ }^{15} \mathrm{Nepal}(49 \%)^{31}$ and Kenya (37.3\%). ${ }^{32}$ This might be due to the difference in study design; the previous studies were facility based. 
Table 4 Univariable and multivariable linear regression analyses of knowledge of preconception care among pregnant women in Mana district, Southwest Ethiopia, 2019

\begin{tabular}{|c|c|c|c|c|c|c|}
\hline \multirow[b]{2}{*}{ Variable } & \multicolumn{3}{|c|}{ Univariable regression } & \multicolumn{3}{|c|}{ Multivariable regression } \\
\hline & $\beta$ & $P$ value & $95 \% \mathrm{Cl}$ & $\beta$ & $P$ value & $95 \% \mathrm{Cl}$ \\
\hline \multicolumn{7}{|l|}{ Residence } \\
\hline Urban & 1.9 & $<0.001$ & 1.0 to 2.8 & 0.1 & 0.868 & -1.0 to 1.2 \\
\hline Rural & 0 & & & 0 & & \\
\hline \multicolumn{7}{|l|}{ Age group } \\
\hline $15-24$ & 1.7 & 0.001 & 0.7 to 2.7 & 0.3 & 0.657 & -1.0 to 1.6 \\
\hline $25-34$ & 0.5 & 0.321 & -0.5 to 1.4 & -0.2 & 0.752 & -1.3 to 0.9 \\
\hline $35-49$ & 0 & & & 0 & & \\
\hline \multicolumn{7}{|l|}{ Women's education } \\
\hline No formal education & 0 & & & 0 & & \\
\hline Primary education & 0.8 & 0.004 & 0.2 to 1.3 & -0.1 & 0.776 & -0.9 to 0.7 \\
\hline Secondary and above & 6.6 & $<0.001$ & 5.8 to 7.5 & 3.6 & $<0.001$ & 2.2 to 5.0 \\
\hline \multicolumn{7}{|l|}{ Husband's education } \\
\hline No formal education & 0 & & & 0 & & \\
\hline Primary education & 1.1 & $<0.001$ & 0.6 to 1.7 & 0.4 & 0.331 & -0.4 to 1.2 \\
\hline Secondary and above & 5.8 & $<0.001$ & 5.0 to 6.7 & 2.3 & 0.001 & 1.0 to 3.6 \\
\hline \multicolumn{7}{|c|}{ History of family planning prior to recent pregnancy } \\
\hline Short acting & 0 & & & 0 & & \\
\hline Long acting & 1.5 & 0.001 & 0.6 to 2.3 & 0.8 & 0.059 & -0.03 to 1.6 \\
\hline \multicolumn{7}{|l|}{ Pregnancy planning status } \\
\hline Planned & 2.3 & $<0.001$ & 1.7 to 2.9 & 1.2 & 0.005 & 0.4 to 2.0 \\
\hline Unplanned & 0 & & & 0 & & \\
\hline Frequency of $\mathrm{ANC}$ visits & 0.7 & $<0.001$ & 0.3 to 1.0 & 0.4 & 0.016 & 0.1 to 0.8 \\
\hline \multicolumn{7}{|l|}{ Pre-existing illness } \\
\hline Yes & 1.7 & 0.002 & 0.6 to 2.8 & 1.5 & 0.014 & 0.3 to 2.8 \\
\hline No & 0 & & & 0 & & \\
\hline \multicolumn{7}{|l|}{ Media } \\
\hline Has media (TV/radio) & 1.6 & $<0.001$ & 1.0 to 2.2 & 0.4 & 0.229 & -0.3 to 1.2 \\
\hline No media (TV/radio) & 0 & & & 0 & & \\
\hline
\end{tabular}

Adjusted for: residence, women's age, women's education, husbands' education, pregnancy status, family planning methods, antenatal care follow-up, follow-up for pre-existing illness and media.

ANC, antenatal care.

Women who attend the health facility for services like ANC may have a higher chance of getting information about PC. Besides, the variation might also be due to low media coverage in Ethiopia.

This study identified factors associated with the women's knowledge of PC. Women and their husbands' educational status was associated with women's knowledge of PC. Women who attended secondary and above education had higher knowledge scores of PC than those who had no formal education. This was similar to studies conducted in Nigeria; Egypt; Adet town, Northwest Ethiopia; and Hawassa, South Ethiopia. ${ }^{25}{ }^{2633-36}$ The similarity might be due to the fact that attending higher educational level provides information about their health and gives people the chance of asking information. It can also enable women to use technologies like the internet as a source of information. Indeed, it enhances the women's decision-making power both at their home and in the community, which directly or indirectly increases their knowledge of PC. In this study, women's knowledge of PC was also determined by their husbands' educational level. Women whose their husbands attended secondary and above education had higher knowledge scores. This highlights the importance of improving the communities' educational status. Pregnancy status determines women's knowledge of PC. We found that women who planned their pregnancy had higher knowledge scores than their counterparts. This finding was similar to a 
Table 5 Binary and multivariable logistic regression analyses of knowledge of preconception care among pregnant women in Mana district, Jimma zone, Southwest Ethiopia, 2019

\begin{tabular}{|c|c|c|c|c|}
\hline \multirow[b]{2}{*}{ Variable } & \multicolumn{2}{|c|}{ Knowledge status } & \multirow[b]{2}{*}{ COR $(95 \% \mathrm{Cl})$} & \multirow[b]{2}{*}{ AOR $(95 \% \mathrm{Cl})$} \\
\hline & Good & Poor & & \\
\hline \multicolumn{5}{|l|}{ Residence } \\
\hline Urban & 25 & 45 & $2.3(1.3 \text { to } 3.9)^{\star}$ & 1.3 (0.6 to 2.9$)$ \\
\hline Rural & 108 & 445 & 1 & 1 \\
\hline \multicolumn{5}{|l|}{ Age group } \\
\hline $15-24$ & 63 & 133 & $4.6(2.0$ to 10.6$) \dagger$ & 2.1 (0.7 to 6.0$)$ \\
\hline $25-34$ & 63 & 289 & 2.1 (0.9 to 4.8 ) & 1.0 (0.4 to 2.8$)$ \\
\hline $35-49$ & 7 & 68 & 1 & 1 \\
\hline \multicolumn{5}{|l|}{ Women's education } \\
\hline No formal education & 35 & 293 & 1 & 1 \\
\hline Formal education & 98 & 197 & $4.2(2.7$ to 6.4$) \dagger$ & $2.9(1.6$ to 5.2$) \dagger$ \\
\hline \multicolumn{5}{|l|}{ Husbands' education } \\
\hline No formal education & 29 & 260 & 1 & 1 \\
\hline Formal education & 104 & 230 & 4.4 (2.8 to 6.8$) \dagger$ & 1.4 (0.8 to 2.7 ) \\
\hline \multicolumn{5}{|c|}{ History of family planning prior to recent pregnancy } \\
\hline Short acting & 71 & 280 & 1 & 1 \\
\hline Long acting & 31 & 68 & $1.8(1.1 \text { to } 3.0)^{\star}$ & $1.4(0.7$ to 2.7$)$ \\
\hline \multicolumn{5}{|l|}{ Pregnancy planning status } \\
\hline Planned & 118 & 305 & 4.8 (2.7 to 8.4$)$ & $3.3(1.4 \text { to } 7.4)^{\star}$ \\
\hline Unplanned & 15 & 185 & 1 & 1 \\
\hline \multicolumn{5}{|l|}{ Frequency of ANC visit } \\
\hline One visit & 4 & 38 & 1 & 1 \\
\hline Two visits & 13 & 117 & 1.1 (0.3 to 3.4$)$ & 0.7 (0.2 to 2.5$)$ \\
\hline Three visits & 22 & 77 & 2.7 (0.9 to 8.4 ) & 1.4 (0.4 to 4.7$)$ \\
\hline Four and above visits & 46 & 89 & $4.9(1.7 \text { to } 14.6)^{\star}$ & $3.8(1.2 \text { to } 11.9)^{\star}$ \\
\hline \multicolumn{5}{|l|}{ Pre-existing illness } \\
\hline Yes & 18 & 28 & $2.6(1.4 \text { to } 4.8)^{*}$ & $4.4(1.9 \text { to } 10.4)^{\star}$ \\
\hline No & 115 & 462 & 1 & 1 \\
\hline \multicolumn{5}{|l|}{ Media } \\
\hline Has media (TV/radio) & 78 & 186 & $2.3(1.6$ to 3.4$) \dagger$ & 1.5 (0.8 to 2.7$)$ \\
\hline No media (TV/radio) & 55 & 304 & 1 & 1 \\
\hline
\end{tabular}

*Statistically significant at $p<0.05$.

†Statistically significant at $p<0.001$.

ANC, antenatal care; AOR, adjusted OR; COR, crude OR.

study conducted in Jordan. ${ }^{21}$ This might be probably due to the fact that women who planned to get pregnant can gather information from different sources like friends, spouses, healthcare providers, media, and so on. It might be also due to those who planned their pregnancy might have a higher educational level.

The study also showed that knowledge scores increase with the frequency of ANC visits. Women who had four or more ANC visits had higher knowledge scores compared with those who attended ANC for one visit. This finding was similar to the studies conducted in Nigeria ${ }^{37}$; $\operatorname{Sudan}^{23}$; and Hawassa, South Ethiopia. ${ }^{25}$ The similarity might be probably due to the reason that during ANC visits, the healthcare providers ask the women for their previous health status history and also inform them about the impact of health status before conception on the current pregnancy. An increase in the frequency of the visits increases the chance of getting information. It might also be due to women who attended ANC visits for four or more times might have a higher educational status.

The finding of this study revealed that being on follow-up for pre-existing medical illnesses had a positive association with knowledge score. This finding was similar to the studies conducted in Brazil; Jordan; Zambia; and 
Adet town, Northwest Ethiopia. ${ }^{16} 303335$ The similarity might be due to the fact that frequent contact with healthcare providers helps to get information about their health and services. In addition, it might also be due to the fact that people with medical illness give more attention to their health than those who do not feel any illness, which enables them to gather information from different sources.

This study has several strengths. One of the strengths is that it is a community-based study that makes it a representation of the true population. It also included both the urban and rural populations which help for the generalisability of the finding to the district. Different analyses were carried out which help for the robustness of the findings. A study did not end without limitations. Recall bias may occur on some questions such as those related to obstetric and gynaecologic factors as pregnant women were asked for history before they conceived. Interviewer bias may also occur.

\section{CONCLUSION}

The finding of this study indicated that women's knowledge of PC is low. The study identified that the educational status of women and their husbands, pregnancy planning status, follow-up for pre-existing medical illnesses and frequency of ANC visits were the predictors of women's knowledge of PC. Women and their husbands' higher educational level, planned pregnancy, being on follow-up for pre-existing medical illnesses and four or more ANC visits increase women's knowledge of PC. Therefore, we advise the collaboration of different stakeholders like the Federal Ministry of Health, non-governmental organisations, media personnel and healthcare providers to work on scaling up health education and health promotion to increase women's knowledge of PC. In addition, the researchers are also recommended to conduct studies on PC among different target groups by using strong study designs.

Contributors FT was involved in the conception, design, data collection and analyses; wrote the draft of the paper. YK, FA and ZB were involved in the design and analyses. All authors were involved in report writing and interpretation; reviewed the study and drafts of the manuscript; and read and approved the final manuscript and agreed for submission.

Funding The authors have not declared a specific grant for this research from any funding agency in the public, commercial or not-for-profit sectors.

\section{Competing interests None declared.}

\section{Patient consent for publication Not required.}

Ethics approval A letter of ethical approval was received from the Institutional Review Board of Jimma University with the reference number IHRPGD/356/19 on 8 March 2019. In addition, the official letter of cooperation was obtained from the Mana district health office. The necessary permission was obtained from Ganda leaders. All the study participants were informed about the purpose of the study, their right to refuse, and assured about the confidentiality of the information they provide. Their informed consent was obtained prior to the interview.

Provenance and peer review Not commissioned; externally peer reviewed.

Data availability statement Data are available upon reasonable request from the corresponding author.
Open access This is an open access article distributed in accordance with the Creative Commons Attribution Non Commercial (CC BY-NC 4.0) license, which permits others to distribute, remix, adapt, build upon this work non-commercially, and license their derivative works on different terms, provided the original work is properly cited, appropriate credit is given, any changes made indicated, and the use is non-commercial. See: http://creativecommons.org/licenses/by-nc/4.0/.

ORCID iD

Firanbon Teshome http://orcid.org/0000-0002-8822-8602

\section{REFERENCES}

1 World Health Organization. Meeting to develop a global consensus on preconception care to reduce maternal and childhood mortality and morbidity (meeting report). Geneva: World Health Organization Headquarters, 2012.

2 Mason E, Chandra-Mouli V, Baltag V, et al. Preconception care: advancing from 'important to do and can be done' to 'is being done and is making a difference'. Reprod Health 2014;11:S8.

3 Johnson K, Posner SF, Biermann J, et al. Recommendations to Improve Preconception Health and Health Care"United States: Report of the CDC/ATSDR Preconception Care Work Group and the Select Panel on Preconception Care. Morbidity and Mortality Weekly Report: Recommendations and Reports 2006;55.

4 Atrash HK, Johnson K, Adams Myron (Mike), et al. Preconception care for improving perinatal outcomes: the time to act. Matern Child Health J 2006;10:3-11.

5 World Health Organization, UNICEF. Trends in maternal mortality: 1990-2015: estimates from who, UNICEF, UNFPA, world bank group, and the United nations population division, 2020.

6 Sustainable T, Goals D. The sustainable development goals report, 2016.

7 Central Statistical Agency (CSA) [Ethiopia] and ICF. Ethiopia demographic and health survey 2016, 2016.

8 Mazza D, Chapman A, Michie S. Barriers to the implementation of preconception care guidelines as perceived by general practitioners: a qualitative study. BMC Health Serv Res 2013;13:36.

9 Dean S, Rudan I, Althabe F, et al. Setting research priorities for preconception care in low- and middle-income countries: aiming to reduce maternal and child mortality and morbidity. PLoS Med 2013;10:e1001508.

10 WHO. Preconception care report of a regional expert group consultation 6-8 August 2013. New Delhi, India: World Heal Organ, 2014.

11 van der Zee B, de Beaufort I, Temel S, et al. Preconception care: an essential preventive strategy to improve children's and women's health. J Public Health Policy 2011;32:367-79.

12 Mason E, Chandra-Mouli V, Baltag V, et al. Preconception care: advancing from 'important to do and can be done' to 'is being done and is making a difference'. Reprod Health 2014;11:S8.

13 American College of Obstetricians and Gynecologists. The importance of preconception care in the continuum of women's healthcare. Committee opinion no. 313. Obstet Gynecol 2005;106:665.

14 Dean S, Rudan I, Althabe F, et al. Setting research priorities for preconception care in low- and middle-income countries: aiming to reduce maternal and child mortality and morbidity. PLoS Med 2013;10:e1001508.

15 Kasim R, Draman N, Kadir AA, et al. Knowledge, attitudes and practice of preconception care among women attending appointments at a rural clinic in Kelantan. Education in Medicine Journal 2016;8.

16 Al-Akour NA, Sou'Ub R, Mohammad K, et al. Awareness of preconception care among women and men: a study from Jordan. $J$ Obstet Gynaecol 2015;35:246-50.

17 Olowokere AE, Komolafe A, Awareness OC. Knowledge and uptake of preconception care among women in Ife central local government area of Osun state, Nigeria. Journal of Community Medicine and Primary Health Care 2015;27:83-92.

18 Stephenson J, Patel D, Barrett G, et al. How do women prepare for pregnancy? preconception experiences of women attending antenatal services and views of health professionals. PLOS One 2014;9:e103085.

19 Bolarinwa OA. Principles and methods of validity and reliability testing of questionnaires used in social and health science researches. Niger Postgrad Med J 2015;22:195.

$20 \mathrm{Kim}$ J, Yon M, Kim C-I, et al. Preconceptional use of folic acid and knowledge about folic acid among low-income pregnant women in Korea. Nutr Res Pract 2017;11:240-6. 
21 Al-Akour NA, Sou'Ub R, Mohammad K, et al. Awareness of preconception care among women and men: a study from Jordan. $J$ Obstet Gynaecol 2015;35:246-50.

22 Rosy T, Babita. S, Vice Principal, Associate Professor, National Medical College Nursing Campus, Birgunj, Nepal. Knowledge on preconception care: an issue among reproductive age women attending GYNAE/OBSTETRIC OPD of national medical college. Int J Adv Res 2017;5:2311-4.

23 Alsammani MA, Kunna A, Adam EM. Factors associated with folic acid knowledge and intake among pregnant women in Sudan. EMHJ 2015;23.

24 Ayalew Y. Women's knowledge and associated factors in preconception care in adet, West gojjam, Northwest Ethiopia: a community-based cross-sectional study 2017;14:15.

25 Kassa A, Yohannes Z. Women's knowledge and associated factors on preconception care at public health institution in Hawassa City, South Ethiopia. BMC Res Notes 2018;11:841.

26 Ayalew Y, Mulat A, Dile M, et al. Women's knowledge and associated factors in preconception care in adet, West gojjam, Northwest Ethiopia: a community based cross sectional study. Reprod Health 2017;14:15.

27 Mirkhan Ahmed H, Jamil Piro T. Knowledge, practice, and attitude of married women about preconception care. Journal of Client-centered Nursing Care 2017;3:37-44.

28 Ghaffari F, Jahani Shourab N, Jafarnejad F, et al. Application of Donabedian quality-of-care framework to assess the outcomes of preconception care in urban health centers, Mashhad, Iran in 2012 Journal of Midwifery and Reproductive Health 2014;2:50-9.

29 Ahmed KM, Elbashir IM, Mohamed S, et al. Knowledge, attitude and practice of preconception care among Sudanese women in reproductive age about rheumatic heart disease at Alshaab and Ahmad Gassim hospitals 2014-2015 in Sudan. Basic Res J Med Clin Sci 2015;4:5
30 Mutale P, Kwangu M, Muchemwa CM, et al. Knowledge and preconception care-seeking practices among reproductive-age diabetic women in Zambia. International Journal of Translational Medical Research and Public Health 2017 Nov;23;1:36-43.

31 Nepali G, Sapkota SD. Knowledge and practice regarding preconception care among antenatal mothers. International Journal of Perceptions in Public Health 2017;1:224-7.

32 Joyce C, Keraka M, Njagi J. Assessment of the knowledge on pre conception care among women of reproductive age in Ruiru SubCounty, Kiambu County, Kenya. Global Journal of Health Sciences 2018;3:82-100

33 Moura ER, Evangelista DR, Damasceno AK. The knowledge of women with diabetes mellitus regarding preconception care and maternal-fetal risks. Revista da Escola de Enfermagem da USP 2012;46:22-9.

34 Umer A, Haile ZT, Ahmadi-Montecalvo $\mathrm{H}$, et al. Factors associated with receipt of Pre-Pregnancy preventive dental care among women in West Virginia: pregnancy risk assessment monitoring system (PRAMS) survey 2009-2010. Oral health \& preventive dentistry 2016;14:413-22.

35 Goshu YA, Liyeh TM, Ayele AS, et al. Women's Awareness and Associated Factors on Preconception Folic Acid Supplementation in Adet, Northwestern Ethiopia, 2016: Implication of Reproductive Health. J Nutr Metab 2018;2018:1-7.

36 Deepti DK. Determinants of knowledge regarding folic acid in periconceptional use among pregnant mothers in southern India. IOSR Journal of Dental and Medical Sciences 2013;4:25-9.

37 Lawal TA, Adeleye AO. Determinants of folic acid intake during preconception and in early pregnancy by mothers in Ibadan, Nigeria. Pan Afr Med J 2014;19. 